\title{
In-vitro Assessment of the Antibacterial Quality of Some Commonly Used Herbal and Non-herbal Toothpastes on Streptococcus mutans
}

\author{
Awah, N. S. ${ }^{1, *}$, Agu, K. C. ${ }^{1}$, Okorie, C. C. ${ }^{1}$, Okeke, C. B. ${ }^{1}$, Iloanusi, C. A. ${ }^{1}$, Irondi, C. R. ${ }^{1}$, Udemezue, O. I. ${ }^{1}$, \\ Kyrian-Ogbonna, A. E. ${ }^{1}$, Anaukwu, C. G. ${ }^{1}$, Eneite, H. C. ${ }^{1}$, Ifediegwu M. C. ${ }^{1}$, Umeoduagu, N. D. ${ }^{2}$, \\ Abah, N. H. ${ }^{3}$, Ekong, U. S. ${ }^{4}$ \\ ${ }^{1}$ Department of Applied Microbiology and Brewing, Nnamdi Azikiwe University, Nigeria \\ ${ }^{2}$ Department of Microbiology, Tansian University, Umunya, Anambra, Nigeria \\ ${ }^{3}$ Federal School of Dental Technology and Therapy, Enugu, Nigeria \\ ${ }^{4}$ Pharmaceutical Microbiology/Biotechnology Unit, Department of Pharmaceutics, Pharmaceutical Technology, Faculty of Pharmacy, \\ University of Uyo, Nigeria
}

Copyright $(2016$ by authors, all rights reserved. Authors agree that this article remains permanently open access under the terms of the Creative Commons Attribution License 4.0 International License

\begin{abstract}
In-vitro assessment of the antibacterial quality of four commonly used brands of herbal toothpastes in comparison with their corresponding non-herbal toothpastes on Streptococcus mutans was examined. Eight brands of commercially available toothpastes comprising of four herbal and non-herbal brands respectively were purchased in a local market in Awka South, Anambra State, Nigeria. The herbal brands selected were designated $\mathrm{AH}, \mathrm{BH}, \mathrm{CH}$ and $\mathrm{DH}$ and their respective non-herbal brands designated $\mathrm{ANH}$, $\mathrm{BNH}, \mathrm{CNH}$ and DNH served as positive controls. The use of distilled water served as negative control. The antibacterial activity evaluation was performed using agar well diffusion method. Different concentrations of toothpastes were made by 2 -fold serial dilution method using sterile distilled water as diluents. Inhibition zones were measured in millimeters after 24hrs. Among the non-herbal toothpastes, triclosan containing toothpaste gave the highest zone of inhibition compared to non-triclosan toothpastes. The herbal toothpaste of each brand gave better inhibition result in comparison with their corresponding non-herbal brands. BH toothpaste gave maximum inhibition followed by $\mathrm{AH}, \mathrm{CH}$ and lastly DH toothpastes. The result of this study indicates that herbal toothpastes are marginally better in inhibiting the growth of Streptococcus mutans; although both herbal and non-herbal toothpastes were equally effective in reducing pathogenic plaque and maintaining oral hygiene.
\end{abstract}

Keywords In-vitro Assessment, Antibacterial Quality, Herbal, Non-herbal Toothpastes, Streptococcus mutans

\section{Introduction}

In Nigeria, as in other developing countries, very significant proportion of dental problems are due to dental biofilms generally known as dental plaque. Dental bio-films are a complex community of microorganisms found on the tooth surface embedded in a matrix of polymers of bacterial and salivary origin. There are several strategies for managing bio-films [1]. It has been reported that more than 500 bacterial strains which are opportunistic may be found in dental plaque [2]. Poor oral hygiene is one of the reasons for accumulation of these microbes and their harmful activities [3]. Tooth brushing with toothpaste is the most widely practiced form of oral hygiene in most countries [4]. The most common oral hygiene aid used to improve the oral health of an individual is the toothbrush [5]. Daily personal oral hygiene (tooth brushing and flossing) is recommended in the interest of good hygiene and for the control of dental plaque [6].

The success of any toothpaste, in part, lies in its ability to eliminate pathogenic oral microflora and deliver fluoride to the teeth which most effectively protects both deciduous and permanent teeth from dental caries [7]. However, fluorides are not the only active ingredients in toothpastes for overall test performance in oral hygiene. Also important are the cleaning abilities of toothpaste provided by abrasives, as the antibacterial qualities, which, in turn, are provided by a variety of substances with different abilities to inhibit the growth of microorganisms in the oral cavity, as well as a number of excipients which are incorporated with specific aims to solve specific problems [8].

The term surfactant is a blend of "surface active agents". Surfactants are usually organic compounds that are amphiphilic, that is, they contain both hydrophobic tails and hydrophilic heads. The hydrophobic and hydrophilic 
moieties partition at the interface between fluid phases with different degrees of polarity and hydrogen bonding such as oil/water or air/water interfaces. Chemically synthesized surfactants are commonly used in petroleum, food and pharmaceutical industries as emulsifiers, wetting agents, cleaning agents and foaming agents. Alkyl sulfates are surfactants used in the production of some tooth pastes $[9,10]$. Among the many substances that inhibit growth of germs in toothpastes are triclosan, xylitol and flourides [11,12]. Nowadays, toothpastes are produced to serve multiple purposes at the same time and, thus, possess a complex chemical composition [13].

Natural toothpastes are those without triclosanor fluoride. They usually contain natural ingredients such as special mineral salts e.g. sodium fluoride and sodium chloride, and plant extracts like lemon, eucalyptus, rosemary, chamomile, sage and myrrh [14]. Several recent studies show that plant and herbal extracts have significant antimicrobial effects against plaque bacteria. As a result, a number of these agents have been incorporated into dentifrices, including toothpastes and mouth rinsers [15].

Hence, the aim of this study was to compare whether there was any significant difference in the antibacterial action between some herbal and non-herbal toothpastes used in Nigeria.

\section{Materials and Methods}

\subsection{Isolation of Bacterial Culture}

Streptococcus mutans was isolated from patients with dental caries attending Federal Dental Clinic, Enugu using sterile swab stick and dental probe. They were inoculated on sodium azide blood agar and identified through various standard microbiological and biochemical procedures [16-18].

\subsection{Source of Toothpastes}

Eight toothpastes comprising of four brands of non-herbal toothpastes and their corresponding herbal toothpastes were purchased from Eke-Awka local market, Awka South of Anambra State, Nigeria. They were designated AH, ANH, $\mathrm{BH}, \mathrm{BNH}, \mathrm{CH}, \mathrm{CNH}, \mathrm{DH}$ and $\mathrm{DNH}$. The labeled compositions of the toothpastes are shown in Table 1.

\subsection{Sample Preparation}

Non-herbal and herbal toothpastes were liquedified by equmolar mixing of the toothpaste in warm, sterile distilled water at the ratio $(1: 1 \mathrm{w} / \mathrm{v})$. Thereafter, the solubilized toothpastes were subjected to two-fold serial dilutions and four working concentrations of $1.0,0.5,0.25,0,125$, $0.063 \mathrm{~g} / \mathrm{ml}$ were obtained.

\subsection{Antibacterial assay}

The antimicrobial activities of different concentrations of the toothpastes were determined using agar well diffusion method described by, Agu et al. (2013) and Adindu et al. (2016) $[19,20]$. Exactly $0.5 \mathrm{ml}$ of overnight culture of Streptococcus mutans adjusted to 0.5 Macfarland Nephelometer standard as described by Cheesbrough (2010) [18], was seeded on Mueller Hinton agar. The plates were allowed to dry for $1 \mathrm{hr}$. Six wells each $6 \mathrm{~mm}$ diameter were made using sterile cork borers in the already seeded Mueller Hinton agar media. Aliquots $(0.2 \mathrm{ml})$ of the respective serially diluted concentrations were introduced into each of the five wells. Water was used as the negative control and was introduced into the sixth well. The assay plates were held at $4^{\circ} \mathrm{C}$ for 1 hour to repress the growth of the seeded culture while promoting diffusion of the oral agents. The plates were incubated at $37^{\circ} \mathrm{C}$ for $24 \mathrm{hrs}$. The antimicrobial activity was evaluated by measuring the diameter of zones of inhibition in millimeter.

Table 1. Ingredients of the Coded Toothpastes used in this Study

\begin{tabular}{|c|l|}
\hline Coded Brands & \multicolumn{1}{c|}{ Ingredients } \\
\hline AH & $\begin{array}{l}\text { Sodium fluoride, Sorbitol, Aqua, Hydrated Silica, Sodium Lauryl sulfate, Aroma (flavour), Cellulose Gum, Sodium Saccharin, } \\
\text { Aloe Barbadensis leaf extract, Limonene, Eucalpytus, Peppermint, Sage, Thyme, Aloe Vera Leaf Extract. }\end{array}$ \\
\hline ANH & $\begin{array}{l}\text { Sodium fluoride, Zinc sulfate, Sorbitol, Aqua (water), Hydrated Silica, Sodium Lauryl sulfate, Aroma (flavour), Cellulose Gum, } \\
\text { Sodium Saccharin, Mica, Sodium Hydroxide, Glycerin, Eugenol. }\end{array}$ \\
\hline BH & $\begin{array}{l}\text { Sodium Monofluorophosphate, , Calcium Carbonate, Aqua, Sorbitol, Sodium lauryl Sulphate, Hydrated Silica, Flavor, Cellulose } \\
\text { Gum, Magnesium Aluminium Silicate, Sodium Saccharin, Sodium Bicarbonate, Eucalyptus globulus oil, Chamomilla recutita } \\
\text { (Matricaria) flower extract, Metaleuca Alternifolia,(Tea tree)leaf oil, Salvia officinalis (sage)oil, Eugenol. }\end{array}$ \\
\hline BNH & $\begin{array}{l}\text { Sodium Monofluorophosphate, Calcium Carbonate, Aqua, Sorbitol, Sodium lauryl Sulphate, Aroma, Cellulose Gum, Sodium } \\
\text { Bicarbonate, Tetrasodium Pyrophosphate, Benzyl Alcohol, Sodium Saccharin, Sodium Hydroxide, Limonene, No sugar. }\end{array}$ \\
\hline CH & $\begin{array}{l}\text { Sodium Fluoride, Aqua, Hydrated silica, Sorbitol, Glycerine, PEG-6, Aroma/flavor, Carrageenaan, Xanthan Gum, Sodium } \\
\text { Fluoride, Sodium Saccharin, Titanium Dioxide, Eucalyptus globulus, Menthaarvensis, Salvia officinalis, Anthemisnobilis, }\end{array}$ \\
\hline CNH & $\begin{array}{l}\text { Sodium Flouride, Aqua, Hydrated Silica, Sorbitol, Glycerine, PEG-6, Sodium Lauryl Sulphate, Sorbitol, Glycerine, PEG-6, } \\
\text { Sodium Lauryl Sulphate, Flavor, Xanthan gum, Sodium Saccharin. }\end{array}$ \\
\hline DH & $\begin{array}{l}\text { Sodium monoflouphosphate, Sorbitol, Silica, Sodium Lauryl Sulphate, Binder, Sodium Saccharin, Aqua, Calcium, Carbonate, } \\
\text { Natural Colour, Flavour with Natural herbs extracts, preservatives. }\end{array}$ \\
\hline DNH & $\begin{array}{l}\text { Sodium monoflouphosphate, Sorbitol, Silica, Sodium Lauryl Sulphate, Binder, Sodium Saccharin, Aqua, Calcium, Carbonate, } \\
\text { triclosan, Natural Colour }\end{array}$ \\
\hline
\end{tabular}


Table 2. Antibacterial activity of herbal and non-herbal toothpaste against concentration

\begin{tabular}{|c|c|c|c|c|c|c|c|c|}
\hline CONC $(\mathrm{mg} / \mathrm{ml})$ & $\mathrm{AH}$ & $\mathrm{ANH}$ & $\mathrm{BH}$ & $\mathrm{BNH}$ & $\mathrm{CH}$ & $\mathrm{CNH}$ & $\mathrm{DH}$ & $\mathrm{DNH}$ \\
\hline 1 & 20 & 14 & 30 & 16 & 19 & 12 & 12 & 9 \\
\hline 0.5 & 17 & 12 & 26 & 14 & 15 & 9 & 11 & 8 \\
\hline 0.25 & 14 & 10 & 22 & 13 & 12 & 0 & 0 & 0 \\
\hline 0.125 & 11 & 0 & 15 & 10 & 10 & 0 & 0 & 0 \\
\hline 0.063 & 0 & 0 & 13 & 0 & 0 & 0 & 0 & 0 \\
\hline
\end{tabular}

\section{Results}

The antibacterial effect showed that all the toothpastes used had growth inhibitory effect on Streptococcus mutans, and the negative control showed no activity. BH toothpaste brand gave the maximum inhibition zone compared to other toothpastes brand. This was followed by $\mathrm{AH}, \mathrm{CH}$ and $\mathrm{DH}$. The herbal toothpastes of each brands used gave higher inhibitory activity compared to their corresponding non-herbal toothpastes. The herbal toothpaste $(\mathrm{BH})$ was effective even at $0.063 \mathrm{~g} / \mathrm{ml}$ giving $13 \mathrm{~mm}$ than others (Table 2).

\section{Discussion}

Streptococcus spp are the most dominant bacterial species in dental plaque and the major pathogens of dental infection [4]. Amongst the Streptococci, Streptococcus mutans is recognized as the main opportunistic pathogen of dental caries which can demineralize the enamel. Poor oral hygiene is considered as a major reason for the accumulation and emergence of this harmful effect [3]. Equally, maintenance of good oral hygiene is the key to the prevention of dental diseases [3].

The most widely practiced oral hygiene method is tooth-brushing with toothpaste [21]. Toothpastes have been widely reported to have different antimicrobial components like triclosan, bromochlorophene, sodium lauryl sulfate (SLS), sodium mono-fluorophosphate (MPF), sodium fluoride (SF), xylitol [4,12,22]. Conversely, herbal toothpaste may not contain all these antimicrobial agents. However, irrespective of this property, herbal toothpastes have been in use for a fairly long period of time and are fast gaining popularity in most parts of Africa, Asia and Europe mainly because they are derived naturally and do not possess harsh chemicals present in most commercially available toothpastes [18]. Tea tree oil, propolis, garlic, neem lemon, eucalyptus, rosemary, chamomile, sage and myrrh and other herbs and spices have all shown proven antimicrobial effects against a range of oral bacteria, including the periodontal pathogens such as [14,23-24]. Many of these have been successfully incorporated into a number of dentifrices, including toothpastes, mouth-wash, mouth gargle, and gels.

Data from the present study show that all the herbal and non-herbal toothpastes used demonstrated wide variations in their activity against the test organism, a feature which may have been largely due to their different antimicrobial active ingredients (Table 1). Evidently, Moran et al, 1988 [22] and Okpalaugo et al.2009 [14] evaluated the in-vitro antibacterial properties of many dentrifices and concluded that not even $50 \%$ of the dentrifices available commercially had antibacterial properties to benefit dental health or antiplaque action. This is contrary to the present study. This may be due to the changes in the manufacturing guidelines that were set after the study was conducted and the addition of newer substances in the dentrifices with better antibacterial and anti-plaque properties $[1,25]$.

The toothpastes having the largest microbial inhibition zone and probably the strongest antimicrobial properties may not be necessarily superior to those found to have smaller zones of inhibition [15]. From the present study, the herbal brands gave higher zones of inhibition than the non-herbal toothpastes. This can be related to the presence of triclosan, sodium MPF and SLS in CNH products (Table 1). Triclosan [5-chloro-2-(2,4-dichlorophenoxy) phenol] has been used for more than 30 years as a general antibacterial [3]. Triclosan has been accepted by the FDA as an antiplaque-antigingivitis therapeutic additive to toothpastes [26]. Hence, toothpastes with triclosan and sodium mono-flouro-phosphate are more effective than toothpastes containing only sodium mono-flouro-phosphate or sodium fluoride as an active antibacterial ingredient. This was confirmed by research done in other comparative studies of non-herbal toothpastes [3-4,7,14].

$\mathrm{CH}$ brand gave better effectiveness against the test organism than the other brands of herbal toothpastes may be because of the greater range of different herbs contained in $\mathrm{CH}$ (Table 1).

Recently, several studies have shown that plant and herbal extracts have significant antimicrobial effects against plaque bacteria. As a result, a number of these agents have been incorporated into dentifrices, including toothpastes and mouth-rinsers [15]. The herbal toothpastes used in this study gave better effectiveness against Streptococus mutans than their corresponding non-herbal toothpaste brands. Shetty et al. (2015) [27] carried out a study of a comparative evaluation of the effect of a herbal dentrifice and a regular dentrifice on beneficial oral microflora and reported that herbal dentrifices are more effective in preservation of oral microflora when compared to regular dentrifices, although both were equally effective in inhibiting the pathogenic microorganisms. Some researchers Ozaki et al., 2006 [25], Tatikonda et al., 2014 [28], George et al., 2009 [29] had 
reported that herbal dentrifice was as effective as non-herbal dentrifices in the control of plaque and gingivitis. Saxena et al. (2011) [30] found in an in-vitro study that herbal dentrifices showed a maximum inhibition zone.

Nevertheless, a contrary report by Peck et al. (2011) [23] on the study of an in-vitro analysis of antimicrobial efficacy of herbal toothpaste on selected primary plaque colonizers showed that non-herbal toothpaste gave better inhibition zone than herbal toothpastes used except for Dentazyme herbal toothpastes which have similar antimicrobial efficacy with the $\mathrm{CH}$. This present study showed that all the herbal toothpaste used were more effective against the test organism than their corresponding non-herbal toothpastes brands. The difference in reports of these two studies may be due to different herbal compositions and ingredients of the toothpastes used in the two studies, as well as geographical environmental factors.

\section{Conclusions}

From the data obtained in the study, it could be deduced that herbal toothpaste show better inhibitory activity against the growth of Streptococcus mutans than the non-herbal counterpart in reducing pathogenic plague and maintaining oral hygiene. It is recommended that further in-vitro and in-vivo studies be carried out on commercially available toothpastes widely used in Nigeria.

\section{Acknowledgements}

We acknowledge the efforts of the entire Laboratory Staff of Microbiology Department, Nnamdi Azikiwe University, Awka, for helping out with the preparation of the various culture media used for the Microbiological Analyses of the various micro organisms used in this study.

\section{REFRENCES}

[1] Maltz, M. 2009. Over-the-counter preventive and therapeutic oral products. Braz Oral Res; 23 (Spec Iss 1):pp 4-7.

[2] Kroes, I., Lepp, P.W., and Reiman, D.D. 1999. Bacterial diversity within the human subgingivalcrvice. ProcNatlAcadSci USA, 96(25):14547-14552.

[3] Prasanth, M. 2011. Antimicrobial Efficacy of Different Toothpastes and Mouthrinses: An In vitro Study. Dental Research Journal, 8(2):85-94.

[4] Sadeghi, M., and Assar, S. 2009. An In vitro Antimicrobial Activity of Ten Iranian-Made Toothpastes. Dental Research Journal, 6(2): 87-92.

[5] Okafor, A.C., Igwesi, S.N., David, E.E., Okolo, V.K. and Agu, K. (2016). Presence of Bacteria With Pathogenic Potential Among Already-Used Toothbrushes From University
Students. American Journal of Life Science Researches, 4 (3): $16-20$

[6] Tinanoff, N., Kanellis, M., and Vargas, C. 2002. Current Understanding of the Epidemiology, Mechanisms, and Prevention of Dental Caries in Preschool Children. Pediatric Dentistry, 24(6): 546-551.

[7] Degiam, Z.D. 2010. An In vitro Antimicrobial Activity of Six Commercial Toothpastes. Thi-Qar Medical Journal. 4(4): 127-133.

[8] Maldupa, I., Brinkmane, A.,Rendeniece, I., and Mihailova, A.2012 Stomatologija Evidence based toothpaste classification, according to certain characteristics of their chemical composition. Baltic Dental and Maxillofacial Journal, 14:12-22.

[9] Anaukwu, C.G., Ezemba, C.C., Anakwenze, V.N., Agu, K.C., Okeke, B.C., Awah, N.S. and Ekwealor, I.A. 2016. Effect of biosurfactant produced by Citrobacter murliniae AF025369 and a synthetic surfactant on degradation of crude oil. EdoriumJournal of Microbiology, 2:1-6.

[10] Anaukwu, C.G., Ezemba, C.C., Anakwenze, V.N., Agu, K.C., Nwankwegu, A.S., Okeke, B.C. and Awah, N.S. 2016. Influence Of Anionic, Cationic And Non-Ionic Surfactants On Growth Of Hydrocarbon Utilizing Bacteria. American Journal of Current Microbiology, 4:10-16.

[11] Milgrom P; Ly, KA; Tut, O; Mancl, L; Roberts, M; Briand, K; Gancio, MJ. Xylitol pediatric oral topic syrup to prevent cáries: a double blind, randomized clinical trial of efficacy. Arch PediatrAdolesc Med. 2009 July ; 163(7): 601-607.

[12] Strassler, H.E. 2012. Toothpaste Ingredients Make a Difference: Patient-Specific Recommendations. Retrieved on 4th March, 2014 fromhttp://d3e9u3gw8odyw8.cloudfront.ne t/toothpaste_ingredients.pdf

[13] Ersoy, M; Tanalp, J; Ozel, E; Cengizlier R; Soyman, M; The allergy of toothpaste: a case report. AllergoletImmunopathol $2008 ; 36(6): 368-70$.

[14] Okpalugo, J., Ibrahim, K., and Inyang, U. 2009. Toothpaste Formulation Efficacy in Reducing Oral Flora. Journal of Pharmaceutical Research, 8 (1): 71-77.

[15] Lee SS, Zhang W, Li Y. The antimicrobial potential of 14 natural herbal dentifrices. Resultsof an in vitro diffusion method study. J Am Dent Assoc 2004;135:1133-41.

[16] Ruoff, Whiley and Beighton. 1999. In Murray, P.R., Baron, E. J., Tenover, J.J., Pfaller, M.A., and Yolken, R.H (Editors). Manual of Clinical Microbiology. 7th Edition. American Society for Microbiology, Washington, D.C.

[17] Holt, J.G., Krieg, N.R., Sneath, P.H., Stanley, J.T., and Williams, S.T. 1994. Bergey's Manual of Determinative Bacteriology. 9th Edition. USA. Lippincott Williams and Wilkins. Pp 532.

[18] Cheesbrough, M. 2010. District Laboratory Practice in Tropical Countries. Part 2. $2^{\text {nd }}$ Edition. Cambridge University Press. South Africa.

[19] Agu, K.C., Igweoha, C.A., Umeh, C.N., 2013. Antimicrobial Activity of the Ethanolic and Petroleum Ether Extracts of Tangerine Seed on Selected Bacteria. International Journal of Agriculture and Bioscience, 2 (1): 22-24. 
[20] Adindu, C.S., Odili, L.C., Nwagu, E.E., Agu, K.C., Awah, N.S., Okeke, B.C., Orjionwe, R.N. 2016. Phytochemical and Antimicrobial Screening of Colagigantea Leaves, Stem and Bark. Universal Journal of Microbiology Research, 4 (2): 49-54.

[21] Ghapanchi, J., Kamali, F., Moattari, A., Poorshahidi, S., Shahin, E., Rezazadeh, F., Khorshidi, H., and Jamshidi S. 2015. In-Vitro Comparison of Cytotoxic and Antibacterial Effects of 16 Commercial Toothpastes. Journal of International Oral Health 2015; 7(3):39-43.

[22] Moran J.M., Addy R., and Newcombe R. 1988. The Antibacterial Effect of Toothpastes on the Salivary Flora. J ClinPeriodontol; 15(3): 193-199.

[23] Peck, M.T., Africa, W.J., Stephen, X.G., Marnewick, J., and Majeed A. 2011. An in-vitro Analysis of the Antimicrobial Efficacy of Herbal Toothpastes on Selected Primary Plaque Colonizers. Int. Journal of Clinical Dental Science: 2(3); 28-32.

[24] Jenner F., Jaleel V, Kulshrestha R, Maheswar G, Rao P, and Kranthi J. 2013. Evaluating the Antimicrobial Activity of Commercially Available Toothpasteson Microorganisms Associated with Diabetes Mellitus. The Journal of Contemporary Dental Practice 14(5): 924-929.
[25] Ozaki, F.; Pannuti, CM.; Imbronito, AV.; Pessotti, W.; Saraiva, L.; de Freitas, NM. etal. 2006. Efficacy of a herbal toothpaste on patients with established gingivitis arandomized controlled trial. Braz Oral Res; 20(2): 172-177.

[26] Davies, R.M., Ellwodd, R.P., and Davies, G.M. 2004. The Effectiveness of a Toothpaste Containing Triclosan and Polyvinyl-methyl Ether Maleic Acid Copolymer in Improving Plaque Control and Gingival Health: A Systematic Review. Journal of Clinical Periodontology, 31:1029-33.

[27] Shetty S, Thoudam B, Bose A 2015. Comaparative Evaluation of the effects of a herbal dentrifice and a regular dentrifice on beneficial oral microflora- A clinic-Microbiologic study. International journal of dentistry and oral health 1(3); 1-6.

[28] Tatikonda A., Dabnath S., Chauban VS., ChaurasiaVR., Taranath M., and Sharma AM 2014. Effects of herbal and Non-herbal Toothpastes on Plaque and Gingivitis: A Clinical Comparative Study. J IntSoc Prevent Communit Dent 4(5); 126-129.

[29] George J, Hegde S, Rajesh KS, Kumar A 2009 The efficacy of a Herbal-based Toothpaste on the Control of Plaque and Gingivitis. IndianJ Dent Res 20: 480-482.

[30] Saxena S., PrashantCM.,Chandu GN. 2011. Laboratorial Evaluation of Antimicrobial Efficacy of Herbal Dentrifice Commercialized in India. Arch Oral Res; 7: 51-60. 